Portland State University

PDXScholar

1979

\title{
Follow-up study of children in six Day and Residential Treatment Service (DARTS) Centers in Oregon
}

Doris M. Beard

Portland State University

L. Gail Bulkley

Portland State University

Follow this and additional works at: https://pdxscholar.library.pdx.edu/open_access_etds

Part of the Mental and Social Health Commons, and the Social Work Commons Let us know how access to this document benefits you.

\section{Recommended Citation}

Beard, Doris M. and Bulkley, L. Gail, "Follow-up study of children in six Day and Residential Treatment Service (DARTS) Centers in Oregon" (1979). Dissertations and Theses. Paper 2818.

https://doi.org/10.15760/etd.2813

This Thesis is brought to you for free and open access. It has been accepted for inclusion in Dissertations and Theses by an authorized administrator of PDXScholar. Please contact us if we can make this document more accessible: pdxscholar@pdx.edu. 


\title{
FOLLOW-UP STUDY OF CHILDREN IN SIX DAY AND \\ RESIDENTIAL TREATMENT SERVICE \\ (DARTS) GENTERS IN OREGON
}

\author{
by \\ DORIS M. BEARD \\ and
}

I. GAIL BULKLEY

\section{A practicum submitted in partial fulfillment. of the requirements for the degree of \\ MASTER OF SOCIAL WORK}

Portland State University 
APPROVED:

Nancy M. Toroloff, Assistan Sof essor, School of Social Work 
TABLE OF CONTENTS

PAGE

LIST OF TABLES ........................ . . . .

LIST OF FIGURES ............................... vi

\section{CHAPTER}

I INTRODUCTION . . . . . . . . . . . . . . I I

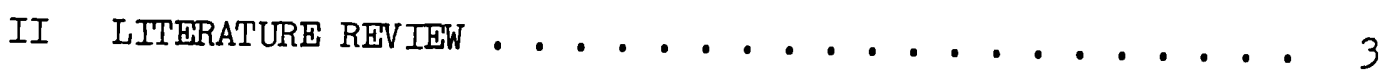

III DESCRIPTION OF THE DAY \& RESIDENTIAL TREATMENT

SERVICES PROGRAM .............. 8

IV METHODOLOGY ................... 15

The Population .............. 15

Families ................ 17

Confidentiality .............. 18

The Interview Schedule . . . . . . . . . 19

Limitations ............ . . 23

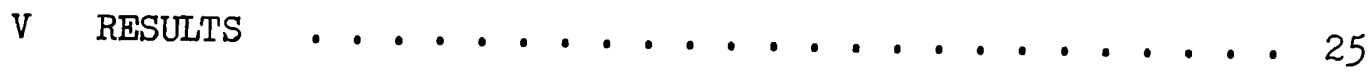

The Population ............. 25

Outcome Categories . . . . . . . . . 27 27

Current Functioning of the 56 Sample Children ... . 31

Past and Current Functioning of 47 Children ..... 42

Summary . . . . . . . . . . . 49 
VI INTERPRETATIONS, CONCLUSIONS, AND RECOMMENDATIONS . . . 50 Interpretations and Conclusions . . . . . . 50 Recommendations ............. 53

A SELECTED BIBLIOGRAPHY . . . . . . . . . . . . . 56 APPENDICES . . . . . . . . . . . . . . . . . 59 APPENDIX A INITIAL LETTER . . . . . . . . . . 59 APPENDIX B FIRST PERMISSION ............. . 60 APPENDIX C SECOND PERMISSION ............. 61 APPENDIX D FOLLOW-UP LETTER . . . . . . . . . . 62 APPENDIX E INTERVIEW SCHEDULE ............ 63 


\section{LIST OF TABLES}

TABLE

PAGE

I Summary of Children in the Population . . . . . . . . . 26

II Distribution of Children by Outcome Category . . . . . . . . 31

III Subjects' Ages in Years at Three Selected Times . . . . . . . 32

IV Age at Follow-up by Outcome Category . . . . . . . . . . 33

V Highlighting of Outcome Categories by Age . . . . . . . . . 33

VI Sex in Relation to Outcome Category . . . . . . . . . 34

VII Relationship Between Outcome Category \& Cohort . . . . . 35

VIII Outcome Categories by Type of Treatment . . . . . . . . 36

IX Outcome Category by Length of Treatment . . . . . . . . 37

X Outcome Categories Relative to Retardation . . . . . . . 38

XI Community Services Relative to Outcome Category . . . . . . 40

XII Numbers of Children Currently Exhibiting Specific Behaviors . 41

XIII Outcome Categories in Relation to Numbers of Problems

Currently Exhibited . . . . . . . . . . 42

XIV Numbers of Behaviors at Entry into the Centers . . . . . . 43

XV Numbers of Problems by Type of Problem at Entry \& Currently . 44

XVI Numbers of Problems at Entry \& CurrentIy . . . . . . . 45

XVII Outcome Categories in Relation to Numbers of Behaviors at

Entry into Centers . . . . . . . . . . . 46

XVIII Outcome Categories in Relation to Parents' Cooperation . . 47

XIX Child's Improvement by Discharge Relative to Outcome Category 48 


\section{LIST OF FIGURES}

FIGURE

1. Distribution of DARTS Monies . . . . . . . . . . 13 


\section{CHAPTER I}

\section{INTRODUCTION}

This study was begun at the request of the Mental Health Division (henceforth known as MHD) of the State of Oregon. The purpose was to conduct a follow-up study on six Day and Residential Treatment Service (henceforth known as DARTS) Centers which are funded by MHD. The purpose of the research was to assess whether or not the Centers are an effective treatment tool. The information acquired by this study will be used to provide information to MHD and the DARTS Center Directors to assist their decision making regarding program direction, and to provide MHD with specific information to be used in preparation for the upcoming state legislative session.

Both researchers had previous working experience with Children's Services Division (henceforth known as CSD). Based on contact with the DARTS Centers through their work experience, the researchers began this study believing that these Centers provide an effective form of treatment. They had a similar belief regarding the cost effectiveness of DARTS treatment (both in human and monetary terms) as opposed to other forms of adult treatment (e.g., hospitalization, long-term outpatient, incarceration, etc.,). In other words, this belief centered on the idea that Centers not only cost less money than maintaining patients on a long-term basis in jail or in the State psychiatric hospital, but that they also help people become more productive citizens. The researchers' willingness to undertake this study was founded on a desire to discover whether, in fact, these beliefs were justifiable. 
H. Roberts Bagwell, M.D., was the liaison between the MHD and this study. Dr. Bagwell is the consulting psychiatrist to the Child and Adolescent Section of MHD; and, as such, is a program consultant to the DARTS Centers. Dr. Bagwell worked jointly with the researchers in a team effort, and was involved in most aspects of this study. He specifically assisted in the development of many parts of the interview schedule, provided some of the statistical analysis, and was the primary communicator between the research team and the state office of Children's Services Division. His assistance was invaluable throughout the research process. 
CHAPTER II

\section{LITERATURE REVIEW}

A literature review was undertaken to find follow-up studies on children who had received treatment from programs similar to the Oregon DARTS program. The Oregon DARTS program serves children through communitybased day and reșidential programs. These children have a variety of problems and are not treated according to specific diagnostic labels. The authors of this study determined initially that the criteria for success would be broad and include satisfactory adjustment to family, school, and community settings. Because of this broad definition of success, and because of the community-based treatment mode, no comparable research was found in the literature review.

The literature review revealed that most follow-up research falls into one of five categories: (1) research concentrating on a specific type of treatment setting (e.g., school, hospital, outpatient clinic); (2) the isolation of a specific diagnostically labelled population (e.g., autistic, schizophrenic); (3) research with a narrowly focused criterion of success (e.g., psychiatric test batteries, school success only); '(4) research in which the program had provided diagnostic evaluation only to the client; and (5) research designed to develop predictive capability.

Many researchers investigated children involved in only one type of treatment setting. The Fuller (1971) study used children exclusively from a school setting. Eisenberg (1956) used children exclusively in day treatment; whereas; the subjects of Goldfarb (1970) and Davids and 
Salvatore (1976) were only involved in residential treatment. The study conducted by Davis, Ryan, and Salvatore (1968) involved hospitalized children; and Levitt, Beiser, and Robertson (1959) used only outpatient clients. The narrow focus of these studies is not comparable to the broader treatment settings of the DARTS Centers. Although a few of the Centers use day treatment exclusively, many of them have both day and residential treatment components; and the children can move back and forth between the two if needed. In addition each Center has a school program which is an integral part of treatment. This academic component was often not a part of the previously mentioned research.

The majority of the located research dealt with a specifically diagnosed population. Eisenberg's (1956) study of autistic children, the studies of psychotic children by Davids, Ryan, and Salvatore (1968) and the studies Goldfarb (1970) conducted on schizophrenic children are all examples of this type of follow-up study. The children treated in the DARTS Centers are a mixture of all diagnostic categories. In addition they include physically and mentally handicapped children with emotional and behavioral problems. None of the studies reviewed had a comparable population group.

The criteria for the successful outcome of the children studied were usually more narrowly focused than the study conducted on the DARTS Centers. In this study, the child's current adjustment in the family, school, and community setting were all assessed in determining the outcome categories. The Fuller (1971) and Levitt, Beiser, and Robertson (1959) studies are examples of research done using behavior in school as the success criterion. (Other research defined success on the basis of a psychiatric test battery; one example is the Levitt, Beiser, and Robertson (1959) research.) In 
contrast the DARTS study concentrates exclusively on observable behaviors rather than intrapsychic elements. In the follow-up research on diagnostic programs, the programs evaluated provided no treatment for the children. Indeed these researchers often divided the children into two groups, those who subsequently received treatment and those who did not. The results of the two groups were then compared. Examples of diagnostic studies include Brown (1963); Rutter, Greenfeld, and Lockyer (1968); Peck and Angevine (1977); Zax, Cowen, Rappaport, Beach, and Laird (1968); and Menolascino and Eaton (1968).

The technique used in the predictive studies generally consisted of looking at a child's pre-treatment history in an attempt to identify trait(s) and/or characteristic(s) which could indicate that the child was going to have serious emotional problems. The study conducted by Silver (1961) is an illustration of this type of study.

Two pieces of research were discovered to have more similarities to these authors' research than any others. Joseph Gold and John M. Reisman (1970) conducted a follow-up study on fifty children who had participated in the day treatment unit of a community mental health center. Forty-eight of the 50 (96 per cent) children were located and included in the research. The scope of the Gold and Reisman research was somewhat more limited because they used children from just one center, and thair only criterion for success was adjustment to a regular classroom. The day treatment unit in which these children were involved used small group, planned academic, and social experiences and parental and child counseling as elements of treatment. In conducting their evaluation, Gold and Reisman used both the child's parent and teacher as reporters. The Gold and Reisman research was conducted as a telephone interview, and participants were asked to respond to a current behavior scale on each child. 
The results of the Gold and Reisman research indicated that 77 per cent of the children studied re-entered public school. However, 70 per cent of them still required some special education program. At the time of follow-up, 66 per cent of the children were described as having less severe symptoms than at the beginning of treatment. According to the evaluation forms, parents and teachers perceived improvement and help differently; however, the overall picture emerged as positive.

'James M. Cunningham, Hester H. Westerman, and Joseph Fischhoff (1956) conducted a follow-up study on 800 children five years after they received outpatient treatment at the Children's Center of Metropolitan Detroit. Of the 800 children selected, 420 ( 52.5 per cent) were actually located and studied. Cunningham used center information at the time of case closing and obtained the parent's estimation of a child's current adjustment by using a pre-designed schedule in a telephone interview. The Cunningham et al., parent interview schedule included the child's overall current adjustment, school adjustment, and whether the original treated symptoms persisted and/or new symptoms had appeared.

Cunningham et al., used three outcome categories to report their results. Their outcome categories were: (1) "satisfactory adjustment" (63 per cent) meant that the child was free of all symptoms and getting along well at home, school, and work/play; (2) "partially satisfactory adjustment" (22 per cent) was defined as having some symptoms which prevented them from getting along as well as possible at home, school, and work/play, and might require further treatment; and (3) "unsatisfactory adjustment" ( 14 per cent) which meant the displaying of severe symptoms which definitely indicated further treatment. 
Results of the Cunningham et al., research indicated that 60 per cent of the children were making an adequate academic adjustment, 14 per cent were having some difficulty, and 25 per cent were doing unsatisfactory work. Information on at-home adjustment varied. Girls (73 per cent) appeared to be making a better home adjustment than did boys (60 per cent). The only child seemed to be adjusting best; whereas, the oldest of siblings was having the most difficulty at home. Children diagnosed as psychoneurotic and having transient situational disorders showed the most favorable overall results; whereas, children with personality disorders and psychosomatic complaints were doing least favorable. There appeared to be no relationship between the completion of the treatment program and the presence or absence of symptoms at time of follow-up. Of the total group of children originally identified as having educational disabilities, 48 per cent had the same educational problems at the time of follow-up. Five years later, 160 children (38 per cent) still retalned symptoms and of these, 43 per cent appeared to be severe enough to warcant additional treatment. However, 60 per cent of the children were symptom free. Improvement indicated by the therapist at case closure was not always sustained five years later, and others who were reported unimproved at the time of case closure were doing adequately at time of follow-up. 
CHAPTER III

DESCRIPTION OF THE DAY AND RESIDENTIAL TREATMENT SERVICES PROGRAM

In 1932, the University of Oregon Medical School established the first child guidance clinic in Oregon. Since that time, treatment services for emotionally disturbed children have slowly increased. In the 1960's three events took place which resulted in the Day and Residential Treatment Services program.

In 1964, Dr. Eugene Taylor (1964) published a study on available mental health services for children; and in 1968, the Greenleigh (1968) report was published. Both of these reports drew similar conclusions: 1. There was a dearth of treatment resources for disturbed children in Oregon

2. Many children were required to travel long distances for treatment

3. Severely disturbed children could often be managed in a community setting

4. Disturbed children usually need a combination of treatment, education, family, and social services in order to progress.

Combined with this information was the findings of Edgefield Iodge's Child Diagnostic Center. Between October 1968 and June 1970, the Diagnostic Center studied 78 children ranging in age from three to 12 and drew like conclusions to the Taylor and Greenleigh reports.

Supplied with this information, the 1971 Oregon Legislature passed House Bill 1869, now ORS $430.705,430.715$ and 430.725 (1977). This legislative mandate authorizes comprehensive mental health services for 
the prevention and treatment of severe emotional disturbances, psychosis, and drug dependency among children throughout the state and was the first clear mandate for advocating, planning, and assuring the delivery of treatment services to emotionally disturbed children.

In order to take advantage of Federal matching funds (Title 4A), the Children's Services Division was designated as the administrative agency for mental health programs for children and the Child study and Treatment Section was developed. In 1974, the Child Study and Treatment Section, now the Child and Adolescent Section, was transferred from CSD to MHD. With this transfer, CSD and MHD established a written agreement giving MHD responsibility for consultation, monitoring, and evaluation of the programs and CSD responsibility for purchasing the services. This division of responsibilities continues to exist today.

The ultimate goal of the legislative mandate is a comprehensive treatment delivery system. However, the starting place was the establishment of the original six DARTS Centers, beginning in 1972. Three residential and three day programs were located in rural communities. Currently there are nine Centers; however, only the original six Centers are used in this study. These Centers treat emotionally disturbed children from the ages of five to 12 who may have mental and/or limited physical disabilities. The Centers treat between eight and 16 children at any one time. The Centers are considered an alternative to institutionalization and, consequently, treat children who are too severely disturbed to be handled by an outpatient center or school system. The DARTS Centers operate on the belief that if a child can be maintained in the community, return to that community will be an easier process. 
The original legislative intent was that treatment programs be developed, administered, and operated by MHD. However in keeping with the State's policy of encouraging private agencies to establish programs from which the State can purchase services, the DARTS Centers were established, and continue to be operated, by local nonprofit corporations. The DARTS Centers are a nontraditional organization model. They are small, community-based Centers and are located in areas of the state with severe shortages of treatment resources. In order to establish high-quality treatment in this type of community setting, the Centers are designed to rely on a nonmedically-oriented program with child care workers being the central treatment agent. Supporting these child care workers are a comprehensive treatment team as well as detailed standards of treatment, planning, and implementation to insure a depth and breadth of treatment.

The centers were established with the following philosophical base:

1. A major focus was on the development of a community treatment system, not just an isolated treatment program in a community. The systems approach encourages communities to use their resources not as independent and isolated parts, but as a whole. The DARTS program is related to and dependent upon other resources of the community. The systems approach takes advantage of the familiar concept that the whole is greater than the sum of the parts. When all resources are used together the result is not just the minimization of duplication, but the multiplication of the effects of each resource.

2. Services are provided to enable the community to become problem-solving. At first impression this appears simple, but its ramifications are complex. It necessitates the community's commitment to problem-solve rather than send its "problem children" away or place them in a center or program to be forgotten. The end result is not how well the emotionally disturbed child can function in a treatment center especially designed for him. It is to reunite the child and his community as quickly and at the most economical level as possible, so that the child will receive the resources he needs to reach his maximum potential and the community's ability to deal with the child is not overtaxed. The 
goal is not cure in six months to five years, but a lifetime of acceptable adjustment in a supportive problem-solving community that makes its resources available whenever needed.

3. While the focus is on children with severe emotional disturbance, DARTS programs are more than a psychiatric facility for children. The treatment philosophy places the highest priority on working with children within their families and their community. Activities with the children are not separated from activities with their families and their ordinary environment.

4. There is recognition of the unique qualities of each program because of the specific resources, concerns and location of each program. As much as possible, program goals and methods are established by the administrative board and professional staff of the private corporation. The state of Oregon purchases treatment services, and the staff of the MHD and CSD units supplement and facilitate the corporation decisions.

5. Treatment: in this enlarged arena requires the sharing of expertise and authority from several different viewpoints and professional foci. It is necessary to interlock medicine, education, child care, social agencies and families in a way that defines areas of legal and professional responsibility within a multi-faceted effort, utilizing the skills and approaches of many treatment modalities in a coordinated manner.

6. The major burden of planning and implementation of the intervention rests on the DARTS program director and his basic child care worker staff. They receive consultation and services from specialists in many fields, principally psychiatry, psychology, social work and education. (Hoyt, 1976)

MHD's Administrative Rule \#34.005 (1976) states that each child must have an individual treatment plan. Prior to establishing this treatment plan, a comprehensive assessment of the child and family must be made within eight weeks of the child's admission; and the written treatment plan must be developed by a multi-disciplinary team within two weeks after completion of the assessment. The assessment is reviewed quarterly, and the treatment plan must reflect any changes in the assessment.

Each Center is an integrated, comprehensive program; and this is reflected in the treatment plans. The individual treatment plans (and, 
as a result, the Centers' programs) must: (1) use community resources whenever possible, (2) make every effort to involve the child's family in all aspects of the treatment process, (3) include a formal educational component, (4) recognize the child's right to enriching play, and (5) provide peer group activities. Involvement of the child's family will vary from Center to Center. Some Centers use traditional family therapy sessions, others use less formal parent groups, and still others have developed structured parent education programs.

P.I. 94-142, passed November 29, 1975, is an extension of civil rights legislation and requires all school districts to provide public education to every eligible child. Prior to the passage of this bill, many Centers hired their own teachers and operated their own schools. In order for this practice to continue and retain Federal funding, the State was required to centralize the administrative process. Rather than do that, Oregon opted to contract with local school districts to provide the educational services. Now, every Center has a school program on site which is operated by the local school district but which still retains the flexibility of individualizing each child's program.

In order to fulfill the treatment needs of each child, MHD requires that all Centers have "the availability of a range of professional expertise sufficient to insure the treatment of choice for each child, . . ." (Hoyt, 1976) The staffing patterns of Centers vary but usually include an Administrative Director (who also often serves as the Clinical Director); clerical positions which include all bookkeeping, secretarial, and administrative assistance tasks; one or two family therapists and/or parent trainers; Iine workers in a ratio of one to every three or four 
children; two or three positions performing tasks including cook, bus driver, bus rider, and housekeeper; and teachers and teacher aides. In addition to these staff members, the treatment teams of all Centers include a consulting psychiatrist and other mental health professionals from community agencies such as CSD and local mental health centers. In order to further insure the needed treatment for each child, all Centers are expected to develop a coordination plan with other community agencies so that needed resources and communication can be shared.

All funding for the day-to-day operation of each DARTS Center is received from MHD, whose liaison monitors each contract monthly. Residential programs receive approximately $\$ 1,600$ a month per child, and day programs receive approximately $\$ 1,100$ a month per child. The Centers are not obligated to raise additional funds unless the local board wants to include items that are not in the MHD-approved budget. Centers usually do not raise additional money. The organization of the funding agencies is best depicted in Figure 1. All State and Federal funding is given to

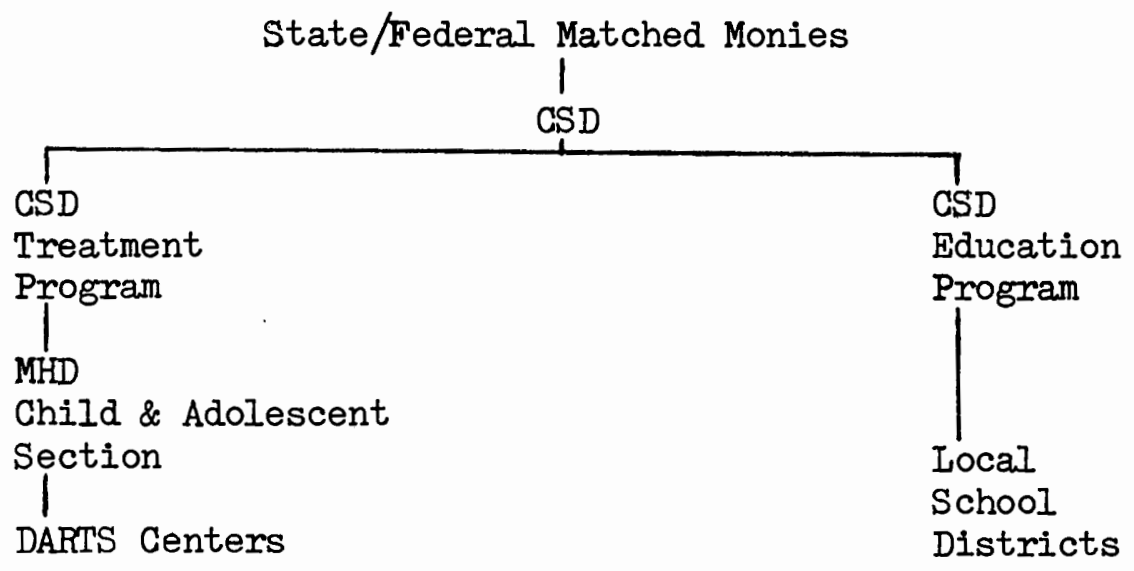

Figure 1. Distribution of DARTS monies.

CSD with the responsibilities previously described. CSD divides these monies between their treatment and education programs. With the total 
treatment money, CSD subcontracts with MHD to carry out those responsibilities that were previously described. MHD in turn funds the basic DARTS Centers' operations. The CSD educational program subcontracts directly with the local school districts to provide the education component at each Center. 


\section{CHAPTER IV}

\section{METHODOLOGY}

The method selected consisted of evaluations of the children's current functioning, as well as their functioning at the time of intake to the Center. A three-part telephone interview schedule was devised, involving multiple reporters for each child. All the children fitting the treatment criteria were included in the study. Attention was focused on the children's observable behaviors rather than their intrapsychic conditions. Selection of children required that their treatment occur within defined dates in order to establish certain lengths of time from discharge to the present. Two time spans were distinguished to allow comparison of children who had been discharged for longer and shorter periods of time.

\section{THE POPULATION}

It had been estimated by the MHD that between 50 and 80 children had been treated and released by six DARTS Centers. As that seemed a feasible number to study, the authors arranged to include all the children who who fit the criteria. From the MHD the authors obtained billing sheets. The sheets submitted by each Center for every month from February 1973 through September 1977 were used. Recording each child by name, type of treatment (day, residential, and mixed), and number of treatment days for each month resulted in a complete list of children. 
Treatment Criteria

In order to remove children who received temporary or diagnostic services only, treatment was defined as ten or more days per month for three consecutive months or three out of five consecutive months. While number of days of treatment is an arbitrary definition, it was workable in terms of measurability and set minimum standards only. Limiting the treatment definition thus eliminated several potential groups of children: those who received only diagnostic services; who may have entered but then were found inappropriate within the first three months; or who, being less disturbed, could be rapidly returned to regular school settings.

Cohorts

A major purpose for doing this research was to determine if length of time since leaving the program affected the child's current adjustment. The hypothesis was that children who had been out of the Centers longer would be doing less well now than more recent graduates. To test this hypothesis, the authors divided the children into two cohorts, $A$ and $B$. Cohort A consisted of those children who left the Centers between June 1976 and May 1977; thus being out of the Centers for one to two years before Summer 1978 when the data was collected. Cohort B consisted of children who left the Centers between June 1975 and May 1976; thus being out for two to three years.

When the authors had identified all the children who fit the treatment criteria; a master sheet was prepared identifying them by name, birthdate, Children's Services Division case number, and date of leaving the Center. The next step was to locate these children, or more accurately, their parents or guardians. 


\section{FAMIIIES}

Locating the Families

One of the administrative complexities of the DARTS Program is that while the Centers are supervised through the MHD a case is opened in CSD for all children enrolled in the DARTS Centers. Also in most cases CSD has responsibility for follow-up care and treatment after the child leaves the Center; therefore, it is more likely to know the current whereabouts of the child. Accordingly, Dr. Bagwell obtained permission from CSD administrators for the authors to review computer records of current CSD clients to locate families at their current addresses. The authors discovered that most cases had been closed, and CSD had no current addresses on most families. GSD did identify 12 children who were wards of the court and committed to CSD for care, placement, and supervision. Dr. Bagwell submitted a formal request to CSD Administrator J.N. Peet, as legal guardian of these children, to obtain permission for release of information. This release would allow the authors to talk directly with caseworkers, foster parents, Center staff, or natural parents about the 12 children. Current addresses were not available from CSD computer files for the large number of children whose cases were closed by CSD. In these situations help was requested from local CSD workers in locating families. In many cases, workers were able to provide at least the parents' names and old addresses. The process of locating families continued through the entire summer of 1978; a few were never located. Among resources used were telephone directories, directory assistance, Center and CSD personnel, school districts, and employers. 
Notifying Parents and Obtaining Their Permission

To introduce the study to parents and prepare them for the authors' telephone call, the authors sent out a letter over Dr. Bagwell's signature describing the study and enclosing a blank permission for release of information form (see Appendices $A$ and $B$ ). The permission form was necessary so the authors could talk to CSD workers about the child's status at entry into the DARTS Center. A self-addressed, stamped envelope was also enclosed for the parents' convenience in returning the permission form. A follow-up letter was sent later in the summer to those parents who had been interviewed, but who had not yet returned the permission form. Also during the summer, the permission form was revised to make it more comprehensive and legally appropriate and to allow the authors to talk with Center staff if needed. This revised form was sent with the follow-up letters (see Appendices $C$ and $D$ ).

\section{CONFIDENTIALITY}

A major issue during the entire data gathering phase of this study concerned confidentiality. At the beginning it was understood that the children were clients of the MHD; and the authors, as representatives of the MHD, could have automatic access to their case records at the Centers and to DARTS Centers' staff. After the study started, some DARTS Center directors began expressing unwillingness to provide any information, including addresses, without explicit permission of the parents. As the authors needed parents' addresses in order to explain the study and request their permission, they began searching for agency position statements regarding this issue, and discovered a lack of clarity regarding confidentiality. Meanwhile the authors had obtained many addresses and proceeded 
with those. The final solution was to ask the Center directors to locate the parents, explain the research, and obtain parents' (verbal) permission for their address to be released to the authors; who then proceeded as above. This procedure was time consuming and awkward.

\section{THE INTERVIEW SCHEDULE}

The research tool consisted of a three part interview schedule to be used in telephone interviews with multiple reporters. The first part requested information about the child's behavior at intake into the DARTS Center. The second included questions about progress during treatment, discharge prognosis, and plan. The third part concerned the child's current functioning (see Appendix $\mathrm{E}$ for the complete interview schedule). Specific information in the first part included where the child lived at intake: with parents, in foster or shelter care, or other. The respondent was asked if the child had been in or out of school, with a tutor, or other. A seventeen point behavior checklist describing the child's behavior at intake was included at this point. The authors modified this behavior checklist from a longer one developed by MHD. which is being considered to obtain consistent intake information among the various Centers. The checklist items chosen for this study were those describing behavior, not intrapsychic conditions. The authors' belief is that behavior is more visible, more tangible, more observable, and more available than intrapsychic measures to the persons who work with the child. The authors' assumption was also that many children would not have received full psychological evaluation. By describing behaviors, the authors avoided labeling the child; a practice they see as potentially 
very destructive for the child. The authors believed that behavioral descriptions would be more consistent than intrapsychic descriptions from the range of lay and professional persons to be interviewed. That is, parents and professional staff would be more likely to "speak the same language" about behavior than about causes or feelings.

The second part of the interview schedule concerned the child's status at the time of leaving the DARTS Center. The questions were: whether the parents had been cooperative with the Center, in what ways the child had demonstrated change, whether the child was considered to have improved overall, whether the child was considered to have improved academically, why the child left the Center, what the discharge plan was, and whether this plan was approved by the Center staff. This last question was designed to clarify ambiguities which might result from the answers about reason for discharge and nature of the discharge plan. For example, several families moved and placed their children in programs in their new communities. Centers' staff might have approved of the discharge plan even though the child continued to need extensive treatment and was not a "successful graduate." The information obtained in this section is relatively soft and subjective, in that it calls for the respondent's judgment and opinion. ,

To obtain responses on these two parts of the interview schedule, the authors talked to CSD workers and in some cases DARTS Center staff. Most information had been recorded in written case records at the time of intake into the DARTS Center. The CSD personnel tumover is high, and the authors usually talked to recent CSD staff who had not known the child at intake to the Center. Thus the written DARTS Center reports and CSD referral information were the usual sources of information available. 
The intake information in CSD files generally consists of some kind of written report from the DARTS Center. In addition, the file occasionally includes detailed progress notes if a CSD worker had been extensively involved with the case over a period of time before the child's placement at the DARTS Center. The DARTS intake reports varied considerably and were sometimes inconsistent from child to child as well as from Center to Center. The authors had considerable difficulty in some cases with translating intake reports into behavior recordable for the behavior checklist. A typical translation might be from "child frequently disobeys teachers and manipulates caseworkers" into the behavior checklist's "difficulty with adults [not his parents] ." More difficulty was encountered with "parents object to child's masturbating;" the authors did not automatically record this as "sexual behavior" on the behavior checklist.

The respondents were told to rate the children as compared to "the average child of that particular age." Respondents' views of what is average undoubtedly play an important part.

The third part of the interview schedule concerned the child's current functioning. For this information, the authors talked to the parent with whom the child was presently living; if the child was in foster care, they talked to the foster parent or the CSD worker. Institutionalized children tended to be committed to CSD, and their CSD workers provided the information. For four children in state institutions, information was obtained from current institutional case files. The authors talked to the parents of one child who was voluntarily placed in a private institution. Custodial relatives and adoptive parents also responded to this part. 
The third part of the interview schedule also contained a variety of open and closed-ended questions focussing on the child's current functioning. Information was sought on the number and whereabouts of living placements since leaving the Center. Moves included those between divorced parents; into foster shelter, or group care; and with relativeș. Respondents were asked whether the living situation was now stable, and whether placement changes were expected. Respondents were asked to describe the child's behavior problems, if any, at home. Regarding school functioning, the authors asked about school year, academic progress, whether the child was in a special education program, and what behavior problems the child had at school.

Community support systems may be important for these children. The authors asked specifically whether CSD, mental health or other counselors, or juvenile authorities had provided services since the child left the Center. Respondents were asked about the length of time these services were provided, and whether legal offenses had been committed. The authors took care to differentiate between juvenile court involvement in dependency or delinquency situations. Another series of questions identified health problems and medications. The authors again used the 17 point behavior checklist, this time for current functioning. Finally the respondents were asked if there had been other life events beyond the child's control that had major impact on the child, such as divorce, death, or lengthy unemployment. Respondents were then invited to comment or add any other pertinent material.

The intent in arranging the third part of the interview schedule was to use the data on each child to form a global assessment. of his/her current 
functioning, thence a measure of "success" or "failure" in points along a continuum. This procedure will be described in Chapter V.

\section{LIMITATIONS}

There are some clear limitations to this study. One limitation involves the authors' inability to measure the child's growth relative to his/her intake behavior. Not enough information was sought about the child at intake to the Center to form any categories comparable to the outcome category ratings. It was simply beyond the scope of this study to delve into this area. Additionally, sufficient data may not exist on this particular group of children to be able to establish baseline category ratings.

Historical information retrieved from old case files presented a limitation. Material was often incomplete and vague; it was often hard for a current CSD worker to find relevant information, especially when the situation was three, four, or five years old. High caseworker turnover meant that the authors usually could not get firsthand information on the child at entry to the Center.

A limitation, or at least a problem, involved the difficulties of dealing with three separate bureaucracies--CSD, MHD, and the Centers themselves. Lack of clear and direct channels of communication between bureaucracies often impeded the flow of written and verbal communication. A related problem was lack of clarity about confidentiality, discussed above.

There was a built-in limitation in choosing to talk to two separate respondents about a single child for past and present information. The 
authors assumed that written materials for past information are less biased than having one person trying to report both past and current information accurately. In some cases, using the parent or parent substitute as a reporter of current functioning seemed to have limitations. For example, several relatives reported the children as so perfect that the authors could not understand why the child had needed help in the first place. Other respondents gave information that proved factually inaccurate; for example, one parent reported CSD had never been involved, and the CSD worker reported extensive contact, terminated only one week previous. In these situations the authors expected that straightforward concrete reporting on the child's daily life would tend to be accurate in most cases.

In retrospect, the authors realize that the behavior checklist is more heavily weighted to acting out behaviors, so that counting the numbers of behaviors depicts acting out children as more problemmatic than other children. In actuality, withdrawn or bizarre behavior may be more serious. These types of behavior are obscured by this particular behavior checklist. Another limitation of this checklist is that respondents were required to choose strictly between either of two alternatives--either the behavior existed or it did not. A continuum of response possibilities would have provided more flexibility.

Thus the research design was established, and the planning stage completed. The authors proceeded to gather and analyze the data. 


\section{CHAPTER V}

\section{RESULTS}

This chapter will present two types of results: simple demographic data on the sample, and the relationship of several pertinent variables to an index of the children's relative success or failure.

\section{THE POPULATION}

The population of the study is comprised of all 70 children who met the criterion of treatment length. Of these 18 are girls and 52 are boys. Cohort A, those children who have been out of the Centers for one to two years, number 32 children; Cohort $B$, those children who have been out for two to three years, number 38. Their ages at the time of analysis range from seven to 16 , with a mean age of $11.74 \quad(N=69$, one child is deceased). The 70 children received a mean of 19.79 months of treatment, with a range of three to over 53 months. These figures represent all that is known about the population of 70 .

Of the 70 children, various problems reduced the number available for study. See Table I for a summary of these problems. The authors were not able to locate eight children, who are designated lost. In most cases, it appears that families had moved out of town with no known destination. One parent had kidnapped the child and disappeared. In another case the mother had remarried and taken her child "somewhere back East." Unlisted telephone numbers account for several "lost" 
children. Five parents refused to participate in the study. Several of the parents refusing felt the need to protect their child from any scrutiny, although they were reassured that the authors did not plan to see

\section{TABLE I}

SUMMARY OF CHILDREN IN THE POPULATION

Explanation

\# of Children

Population 70

Deceased 1

Lost 8

Refused 5

Complete Data Obtained 47

Current Data Only Obtained

9

In The Sample

56

or talk to any child directly. Other parents refused because they were angry with the Centers. The authors tried without success to persuade these parents that negative as well as positive comments about the Centers were of interest. One child had died, and it was deemed inappropriate to contact the parents. Of the population of 70 , the authors talked with parents or guardians of 61 , or 87 per cent of the children. Fifty-six parents (80 per cent) agreed to participate in at least one part of the study. The rest of the results will reflect what is known about the 56 (and in some cases fewer than 56) who were actually studied.

As outlined in Chapter IV, parents were requested to sign a permission for release of information form so that the authors could obtain 
the information from earlier treatment records. Releases were obtained for 47 of the 56 children. Some parents stated their refusal to sign the releases, often displaying animosity or distrust toward CSD, the Center, or "authorities" generally; others simply did not want to stir up the past. Some parents agreed to sign the release and were quite receptive to the study but failed to return the permission form. The sample studied thus includes 47 children on whom complete information was gained, plus nine other children on whom only current information was obtained.

As noted in Chapter IV, 12 of the 70 children are committed to CSD's guardianship. All information was obtained on these children.

\section{OUTCOME CATEGORIES}

It is necessary to digress here from reporting of actual results to present a key methodological tool employed by the authors, the rating of each child's current functioning. The rating employs a five point continuum regarding each child's relative "success" or "failure" in the community at the time of follow-up. These outcome categories will later be discussed in relation to other variables.

After the data collection was completed, a panel, consisting of the authors and Dr. Bagwell, rated each child's current functioning according to the information provided by the parent or guardian. Factors considered were: living arrangements, home stability, behavior problems at home and school, school programs, use of community services, behavior checklist, any presence of mental retardation or health problems. The ratings (hereafter called outcome categories) were developed informally 
and were adjusted to fit the behaviors presented by this group of children. After the entire group of 56 were classified, the panel refined the definitions and reviewed each individual's information for a second time. The initial categorization divided the children into four outcome categories. The refinement of definitions and the second categorization resulted in five outcome groups. The reader is reminded that the categories were designed for these specific children, and might not be readily transferred to another group of children.

The definitions of the five outcome categories are as follows:

\section{Success}

Outcome Category I describes a child who has been stable in all respects (living arrangements, school, and community) for at least three months and has parent(s) or parent substitutes who are committed to the child. This child receives no community services for emotional problems, and has virtually no problems. A hypothetical child in Outcome Category I is an $I 1$ year old boy, A, who has always lived at home; with no behavior problems at home or school. A is at grade level, is healthy, receives no community services. A is still somewhat immature and has an attention span of only ten to 15 minutes, otherwise he is an average normal child.

\section{Partial Success}

Outcome Category II describes a child who has been stable and has parent(s) or parent substitutes who are committed to him. However, this child continues to have a few problems for which he gets help from some community services. These services might include special education 
classes. Physically handicapped and mentally retarded children could not attain higher than a II rating in this scale on the assumption that they will always need some community services. In order not to discriminate against these children, the panel agreed to consider both Outcomes I and II Successes. An Outcome Category II child might be B, a 12 year old boy who has always lived at home. $B$ is retarded and attends a special education class. B fights with his siblings more than an average amount. CSD has provided supportive services to the family. B still has problems with demanding attention, truanting, and problem solving.

\section{Borderline}

Outcome Category III describes a child who could go either way later in life. The child is living in a family setting, but the placement is not stable. Parents' commitment to the child is waning. More and more serious problems are present and more services are being provided. Category III may also include children who act out, and are out of control; but are not institution bound. A strongly dysfunctional family may tip a child into this category. An Outcome Category III child might be $\mathrm{C}$, a 13 year old girl. C's parents are frustrated with her manipulations and lying, and they worry about leaving her alone in the home. $\mathrm{C}$ is described as hyperactive but receives no medication. While $C$ is capable of good academic work, she often refuses to complete assignments. C attends a special class for behaviorally disordered children. She sees a school psychologist regularly for counseling. Her parents fear she will become sexually active soon, and she threatens to run away. She has not committed any juvenile offenses. $C$ still has a list of six current problem behaviors. C's parents threaten her with foster home placement. 
IV. Preinstitutional

Outcome Category IV describes a child who is living in a home setting or in group care in a community setting. The parents have virtually given up on the child. There are substantial problems and services provided. Institutional placement is expected in the future, as the child apparently cannot adjust to a family setting. D, a 13 year old girl, is an example of Outcome Category IV. D, who cannot live with her natural parents, has lived in several foster families, a group home, and relatives' homes. D's current placement is deteriorating, and her CSD caseworker is looking for a group living resource with a treatmentoriented approach. D attends a learning disabilities class, and has many behavior problems at school as well as at home. She has received extensive mental health counseling. D has nine problem behaviors identified on the checklist.

V. Institutional

Outcome Category $\mathrm{V}$ describes a child who is placed in a public or private, 24 hour, out-of-community facility which has an active treatment program. The treatment is largely around issues of emotional or behavioral disturbance. For example, a child who is a Fairview patient might be counted in this category if she or he has significant emotional problems in addition to severe mental retardation. It should be emphasized that Outcome $V$ does not mean that the child made no progress through DARTS treatment; some children may have progressed beyond their entry behavior, but not enough to exclude institutionalization. A hypothetical example of an Outcome $V$ child is $E$, an 11 year old boy, who is committed to CSD, and placed in a private residential treatment program. 
$E$ is manipulative, steals, is aggressive, and has trouble relating to peers. He receives special education schooling, and has ten problem behaviors listed on the behavior checklist. His family relations are tenuous.

\section{CURRENT FUNCTIONING OF THE 56 SAMPLE CHILDREN}

With this synthesis of most items on current functioning into a global rating for each child, the data analysis can proceed. The distribution of children by outcome categories is presented in Table II. The top two, middle one, and bottom one categories comprise roughly onethird each of the sample. This equal relationship was not preestablished.

This chapter will further be subdivided by reporting first what is known about all 56 children's current functioning, and then what additional data was collected about the 47 children on whom full current and past information was obtained. Many variables will be presented, first,

\section{TABLE II}

DISTRIBUTION OF CHILDREN BY OUTCOME CATEGORY

Outcome Category

I

II

III

IV

V

Total

$$
f
$$

4

15

19

10

8

56
14.3

$\%$

7.1

26.8

33.9

17.9

100.0 
by simple numerical reporting, and then, in relation to the outcome categories. Where pertinent, chronological time summaries will also be presented.

$\underline{\text { Age }}$

The ages of the children at entry into the Centers, on leaving the Centers, and at time of analysis (October 1, 1978) are presented in Table III. The mean age of the 56 children at time of analysis was 11.86 years, with ages ranging from seven to 16 years. Table IV presents current age relative to outcome category. The question had arisen whether younger or older children might best profit by DARTS treatment. Table $\mathrm{V}$ presents a further distillation of age categories and outcome categories to highlight some important results. Tables IV and V indicate that children who enter at younger ages do better than older children.

\section{TABLE III}

SUBJECTS' AGES IN YEARS AT THREE SELECTED TIMES

Years Entry to Center Exit from Center At Time of Analysis

\begin{tabular}{lrrr}
$3-4$ & 3 & & \\
$5-6$ & 9 & 5 & 3 \\
$7-8$ & 16 & 6 & 6 \\
$9-10$ & 23 & 23 & 25 \\
$11-12$ & 5 & 20 & 19 \\
$13-14$ & & 2 & 3 \\
$15-16$ & & & 56 \\
Totals & 56 & 56 & \\
\hline
\end{tabular}


TABLE IV

AGE AT FOLLOW-UP BY OUTCOME. CATEGORY*

\begin{tabular}{ccccccc}
$\begin{array}{c}\text { Outcome } \\
\text { Category }\end{array}$ & $7-8$ & $9-10$ & Age at Follow-Up & $13-14$ & $15-16$ & Subtotals \\
\hline I & 1 & 1 & 2 & & & 4 \\
II & 2 & 2 & 8 & 3 & & 15 \\
III & & 1 & 12 & 4 & 2 & 19 \\
IV & 2 & 2 & 6 & & 10 \\
V & & & 1 & 6 & 1 & 8 \\
Totals & 3 & 6 & 25 & 19 & 3 & 56 \\
\hline
\end{tabular}

*Age at follow-up refers to age as of October 1, 1978.

TABLE V

HIGHLIGHTING OF OUTCOME CATEGORIES BY AGE

\begin{tabular}{lccc} 
Age at Entry & $\mathrm{n}$ & $\begin{array}{c}\text { "Success" } \\
\mathrm{f}\end{array}$ & $\begin{array}{c}\text { outcome categories (I \& II) } \\
\text { 46-93 Months }\end{array}$ \\
\hline 18 & 11 & 61 \\
$94-114$ Months & 20 & 6 & 30 \\
$115-140$ Months & 18 & 2 & 11
\end{tabular}

$\begin{array}{lccc}\text { Age at Entry } & \mathrm{n} & \begin{array}{c}\text { Failure" outcome categories (IV \& V) } \\ \%\end{array} & \begin{array}{c}\text { f } \\ \text { 46-93 Months }\end{array} \\ & 18 & 3 & 16.7 \\ \text { 94-114 Months } & 20 & 5 & 25.0 \\ \text { 115-140 Months } & 18 & 10 & 55.5\end{array}$


$\underline{\text { Sex }}$

There were 42 boys and 14 girls in the sample of 56. The authors were interested in discovering the existence or nonexistence of any sexbased differences in treatment success. Table VI presents data on outcome categories for each sex. Percentage figures are also presented because of unequal sample sizes. While the numbers and percentages seem to indicate that males achieve higher success than females, a chi-square test shows no significant difference.

\section{TABLE VI}

SEX IN RELATION TO OUTCOME CATHGORY*

\begin{tabular}{ccccc}
$\begin{array}{l}\text { Outcome } \\
\text { Category }\end{array}$ & $f$ & Males & $\%$ & Females \\
\hline I & 3 & 7.2 & 1 & 7.1 \\
II & 13 & 31.2 & 2 & 14.3 \\
III & 14 & 33.6 & 5 & 35.7 \\
IV & 6 & 14.4 & 4 & 28.6 \\
V & 6 & 14.4 & 2 & 14.3 \\
Totals & 42 & 100.8 & & 100.0 \\
\hline & & & 14 & \\
\hline
\end{tabular}

\section{Cohorts}

As explained in Chapter IV, the sample was divided into two cohorts representing differing lengths of time since the children had left the Centers. Cohort A, the group of children who had been out of the Centers for one to two years, had 26 members. Cohort $B$, the group of children who had been out for two to three years, had 30 members. Table VII shows how 
the cohort members did with regard to outcome category.

TABLE VII

RELATIONSHIP BETWEEN OUTCOME CATEGORY AND COHORT*

\begin{tabular}{ccccc} 
Outcome & \multicolumn{2}{c}{ Cohort A } & \multicolumn{2}{c}{ Cohort B } \\
Category & 2 & 7.7 & 2 & 6.7 \\
I & 7 & 26.9 & 8 & 26.7 \\
II & 7 & 26.9 & 12 & 40.0 \\
II & 5 & 19.2 & 5 & 16.7 \\
V & 5 & 19.2 & 3 & 10.0 \\
Totals & & & & \\
\hline & 26 & 99.9 & 30 & 100.1 \\
\hline
\end{tabular}

The authors were interested in knowing whether the length of time since discharge had any effect on children's current functioning. In other words, would the treatment results deteriorate over time. While Outcome Categories III and IV showed differences between Cohort A and B, a chi-square reveals no significance.

\section{Types of Treatment}

The children received three types of treatment, depending on the Centers' available facilities and the specific plan for each child. Strictly day treatment was provided 34 children; completely residential treatment was given eight, and 13 children received mixed treatment. This "mixed" category' reflects two types of arrangements: five-day residential care with weekends in another setting (usually own family or foster family), or changing from residential to day treatment and vice 
versa. Both types of mixed treatment were common. Table VIII presents material relating outcome category to type of treatment. In this analysis, children in day treatment appear to display more favorable results. However, many other factors may be involved and will be discussed in Chapter VI.

\section{TABLE VIII}

OUTCOME CATEGORIES BY TYPE OF TREATMENT

\begin{tabular}{rrrrrrr}
$\begin{array}{l}\text { Outcome } \\
\text { Category }\end{array}$ & \multicolumn{1}{c}{ Day } & \multicolumn{1}{c}{ Residential } & \multicolumn{2}{c}{ Mixed } & \multicolumn{1}{c}{ f } & $\%$ \\
\hline I & 1 & 5.7 & 1 & 12.5 & 1 & 7.7 \\
II & 13 & 37.1 & 1 & 12.5 & 1 & 7.7 \\
III & 13 & 37.1 & 1 & 12.5 & 5 & 38.5 \\
IV & 3 & 8.6 & 3 & 37.5 & 4 & 30.8 \\
V & 4 & 11.4 & 2 & 25.0 & 2 & 15.4 \\
Totals & 34 & 99.9 & 8 & 100.0 & 13 & 100.1 \\
\hline
\end{tabular}

\section{Length of Treatment}

The children received widely varying lengths of treatment, as presented in Table IX. The reader is reminded that the criterion for inclusion in the study was a minimum of three months treatment. The range of treatment length was from three months to over 53 months; several children had started treatment prior to the earliest months available on the billing sheets. The mean length of treatment was 19.7? months. Table IX also presents data on the outcome categories relative to the length of treatment. A chi-square test shows no significant difference in outcome based on different treatment lengths. 
TABLE IX

OUTCOME CATEGORY BY LENGTH OF TREATMENT*

Outcome

Months

Category

$3-12$

$13-24$

$25+$

Totals

I

1

2

1

4

II

6

4

5

15

III

5

8

6

19

IV

6

1

3

10

V

1

4

3

8

Totals

19

19

18

56

$x^{2}=8.724, p \leq .05$, d.f. $=8$, not significant.

Retardation and Health Factors

Of the 56 children, the authors concluded that ten ( 17.8 per cent) are mentally retarded. Although the Centers are not designed specifically to treat retardation, these children are accepted if they also have significant emotional or behavioral difficulties. The reader is reminded that by definition retarded children could not attain higher than an Outcome Category II. Table $\mathrm{X}$ presents data relative to the outcome categories and presence of mental retardation, by numbers and percentage figures. Although the raw data appear to indicate that retarded children do less well, a chi-square treatment indicates no significant difference. 
TABLE $X$

OUTCOME CATEGORIES RELATIVE TO RETARDATION*\#

\begin{tabular}{rrrrr}
$\begin{array}{l}\text { Outcome } \\
\text { Category }\end{array}$ & $\begin{array}{c}\text { Retarded Children } \\
f\end{array}$ & $\%$ & $\begin{array}{c}\text { Non-Retarded Children } \\
\text { I }\end{array}$ & $\begin{array}{c}\text { C } \\
\text { I \& II }\end{array}$ \\
III & 3 & 30 & 16 & 34.8 \\
IV & 3 & 30 & 16 & 34.8 \\
V & 1 & 10 & 9 & 19.6 \\
& 3 & 30 & 5 & 10.9 \\
Totals & 10 & 100 & 46 & 100.1 \\
\hline
\end{tabular}

* By definition, mentally retarded children could not achieve an Outcome Category I rating.

$\# x^{2}=2.7649, p \leq .05$, d.f. $=3$, not significant.

Seventeen major chronic health problems are present among 15 children in the study; two children have multiple problems. Two children have cerebral palsy and six have some form of seizures. The authors define hyperactive children strictly--only those who receive medication for that condition. Four children are currently hyperactive. Other significant medical problems noted are partial paralysis, severe chronic herpes infections, scoliosis, legal blindness (corrected with glasses); and muscular dystrophy; each represented by one child. Children with health problems are widely diverse in their outcome categories.

\section{$\underline{\text { School Placement }}$}

School placements vary among the 56 children, and in some cases parents were unclear about what, if any, special education services are provided. Thus this data may not be accurate. In speaking with parents, the authors tried to limit the definition to certifiable special education programs, whether for emotional, intellectual, physical, or behavioral 
disabilities. Simple tutoring with the child enrolled in a regular classroom is not counted, nor is the child who is several grades behind if she or he is not placed in a special class. Of the 56 children, 11 spend less than half of each day in a special setting, while 22 spend more than half of each school day in such settings. Thus 33 (58.7 per cent) continue to be identified by schools as getting some special education services. Of the 33 children, 25 receive special education services in the home community's public schools, while eight are in outof-community schools, institutional settings, or private schools.

\section{Community Services}

The authors asked specifically whether certain community services, besides schooling, had been provided since discharge from the Centers. CSD has provided services to 31 children. Mental health counseling, from public or private sources, has been provided for 26 children. In a few of these cases, the counseling is done by a school counselor, psychologist or social worker, but the work has often focused on other than school concerns. Eight children have received services from juvenile authorities for delinquent or status offenses; four of these eight; plus uncounted others, have also been involved with the juvenile courts in dependency matters at some time in their lives. See Table XI for a comparison of community services used relative to outcome category. 
TABLE XI

COMMUNTTY SERVICES RELATIVE TO OUTCOME CATEGORY*

Outcome

Community Services Provided

Category

CSD

Other Counseling

Juvenile Dept.

I

II

III

IV

V

Totals
2

6

3

2

8

3

8

2

1

8

* Some children are using more than one service.

Behavior Checklist

The behavior checklist, completed by the parent or guardian reflects current problem behaviors exhibited by the child. In speaking with respondents, the authors identified these activities in terms of behaviors; however, the definitions of these behaviors are intended to represent problems only if they exist to a greater degree than with average children of the same age. Thus, in this and the following sections, the terms "behaviors" and "problems" will be used interchangeably. Taken on a strictly numerical basis, the most common single behavior present currently is low level of frustration, with 40 children exhibiting it to a degree identified as being a significant problem in comparison to the average child of that particular age. Other most common problem behaviors are demanding attention $(f=37)$, non-compliance $(f=36)$, peer relations $(f=37)$, and short attention span $(f=38)$. The least common are (victim of) sexual abuse ( $f=0)$, fire setting $(f=2)$, truancy $(f=7)$, and substance 
abuse $(f=2)$. A complete list of behavior categories with the numbers of children identified as exhibiting each problem currently is found in Table XII. Of the 17 possibilities on the checklist, the range of current behaviors reported is zero to 13.

\section{TABLE XII}

NUMBERS OF CHILDREN CURRENTLY EXHIBITING SPECIFIC BEHAVIOR PROBLEMS: $\mathrm{N}=55^{*}$

Behavior Problem

Running

Sexual

Sexual abuse (victim of)

Overly aggressive

Demands attention

Non-compliance

Adult relations

Fire setting

Peer relations

Familial relations

Truancy

Short attention span

Low level of frustration

Low self-image, withdrawn, suicidal thoughts, depression, loneliness

Excessive worrying-unreasonable fears

Self-help - problem-solving

Substance abuse f

8

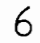

0

27

37

36

25

2

37

22

7

38

40

31

17

29

2

* Most children had several problems reported; one parent was unable to complete the behavior checklist. 
The reader is reminded that the behavior checklist items obtained from the parent or guardian regarding current functioning were used in establishing the overall outcome category ratings. As such, a comparison of outcome categories and numbers of types of behaviors represents a tautology. To validate the outcome category concept per se, a comparison should indicate close agreement. See Table XIII for a comparison of outcome categories and current functioning as measured by number of behaviors on the behavior checklist.

\section{TABLE XIII}

OUTCOME CATEGORIES IN RELATION TO NUMBERS OF PROBLEMS CURRENTLY EXHIBITED

\begin{tabular}{|c|c|c|c|c|c|c|c|}
\hline \multirow[b]{2}{*}{$\begin{array}{l}\text { Outcome } \\
\text { Category }\end{array}$} & \multicolumn{7}{|c|}{ Numbers of Behaviors } \\
\hline & $0-1$ & $2-3$ & $4-5$ & $6-7$ & $8-9$ & $10-11$ & $12-13$ \\
\hline$I$ & 1 & 2 & 1 & & & & \\
\hline II & 4 & 3 & 2 & 4 & 1 & & \\
\hline III & & 1 & 4 & 6 & 4 & 3 & 1 \\
\hline IV & & & 2 & & 5 & 1 & 2 \\
\hline V & & & 1 & 1 & & 5 & 1 \\
\hline Totals & 5 & 6 & 10 & 11 & 10 & 9 & 4 \\
\hline
\end{tabular}

* $\mathrm{N}=55$ because one parent could not complete the checklist.

PAST AND CURRENT FUNCTIONING OF 47 CHILDREN

In addition to the data on the current functioning of the 56 children presented above, the authors were able to obtain additional information on 47 of those children pertaining to their entry into and discharge from the Centers. For this earlier data, the authors talked to 
CSD and Center staff, who obtained the information from CSD referral materials and Center intake reports.

\section{Behavior Checklist}

The 17 point behavior checklist described above was also used to identify problem behaviors of the child when he or she entered the Center. Again a problem was defined as existing for a child only if it appeared more severe than in an average child of the same age. See Table XIV for a breakdown of the numbers of children exhibiting certain numbers of problem behaviors at entry into the Centers. On a simple numerical basis, the most common behavior problem was with peer relations which 46 children exhibited. Other very frequent problems were: noncompliance $(f=40)$, familial relations $(f=41)$, low level of frustration $(f=40)$, and low selfimage, withdrawn, suicidal thoughts, depression, or loneliness $(f=40)$. The least common problems at entry were running ( $f=8$ ), (victim of) sexual abuse $(f=3)$, fire setting $(f=6)$, truancy $(f=4)$, and substance abuse $(f=2)$.

\section{TABLE XIV}

NUMBERS OF BEHAVIORS AT ENTRY INTO THE CENTERS

Numbers of Behaviors

$4-5$

$6-7$

8-9

$10-11$

12-13 f

2

$?$

14

18

6

47
$\%$

4.2

14.?

29.4

37.8

12.6 
Some of these last problems may be age related; for example, truancy, running away, and substance abuse are more commonly associated with adolescents than with younger children. Of the 17 possibilities on the checklist, the most and least number of problems at entry reported for an individual child were 13 and four respectively. See Table XV for a

\section{TABLE XV}

NUMBERS OF PROBLEMS BY TYPE OF PROBLEM AT ENTRY AND CURRENTLY: $N=46 *$

Behavior Problem At Entry Currently

Running

Familial relations

Truancy

Short attention span

Low level of frustration

Low self-image, withdrawn, suicidal

thoughts, depression, loneliness

Excessive worrying - unreasonable fears

Self-help - problem-solving

Substance abuse
7

10

3

32

38

39

34

6

45

40

31

30

21

2

31

18

4

4

35

33

39

34

39

25

19

13

34

24

2 
complete list of entry problems with the number of children having that problem and for a comparison of entry behaviors and current behaviors. Finally, see Table XVI for a comparison of numbers of problems before treatment and currently; and Table XVII for a comparison of entry problems and outcome categories.

TABLE XVI

NUMBERS OF PROBLEMS AT ENTRY AND GURRENTLY*

\begin{tabular}{ccccc} 
Numbers of & \multicolumn{2}{c}{ At Entry } & \multicolumn{2}{c}{ Currently } \\
\hline Behaviors & $f^{\text {Aty }}$ & \multicolumn{1}{c}{$\%$} \\
$0-1$ & & & 5 & 9.1 \\
$2-3$ & 2 & 4.3 & 6 & 10.9 \\
$4-5$ & 7 & 15.2 & 10 & 18.2 \\
$6-7$ & 14 & 30.4 & 11 & 20.0 \\
$8-9$ & 17 & 37.0 & 10 & 18.2 \\
$10-11$ & 6 & 13.0 & 9 & 16.4 \\
$12-13$ & & & 4 & 7.3 \\
Totals & 46 & 99.9 & 55 & 100.1
\end{tabular}

*Ns $=46$ and 55 because one parent could not complete the checklist. 
TABLE XVII

\section{OUTCOME CATEGORIES IN RELATION TO NUMBERS OF \\ BEHAVIORS AT ENTRY INTO CENTERS*}

\begin{tabular}{cccc}
$\begin{array}{c}\text { Outcome } \\
\text { Category }\end{array}$ & $4-7$ & Numbers of Behaviors@ \\
\hline I & 1 & $8-9$ & $10-13$ \\
II & 4 & 3 \\
III & 3 & 5 & 2 \\
IV & 1 & 4 & 9 \\
V & & 2 & 4 \\
& & 3 & 5 \\
Totals & 9 & 14 & 23 \\
\hline & *N=46 because one parent could not complete the checklist. \\
@Note that the range of numbers differs in these categories.
\end{tabular}

As Tables XV and XVI indicate, some frequency changes in behavior did occur from the point of entry to the present time; however, these are not dramatic changes. The authors' subjective impressions are that children did change more than a comparison of the behavior checklists indicates. There are several possible explanations. The general.limitation of having two reporters may relate to parents being perhaps not aware of what constitutes the "acceptable" behavior of an average child. The questions as posed on the behavior checklist may have been insensitive or have lacked clarity. When parents were asked earlier in the schedule to describe in their own words their child's home and school behavior, their responses were spontaneous and "rang true." Completing the behavior checklist was a more passive experience for parents, and perhaps exaggerated the parents' understanding of what constituted a problem for their child. On the other hand, the behavior checklist did attempt to 
pinpoint specific behaviors that may have been overlooked or generalized by parents in the open-ended questions.

Parents' Cooperation During Treatment

Respondents were asked if the parents had been cooperative with the Center during treatment. Table XVIII presents a tabulation of parents' cooperation relative to the outcome categories. There was no significant relation between parents' cooperation and outcome category; however, there was a trend toward children in Outcomes IV and V having less cooperative parents.

TABLE XVIII

OUTCOME CATEGORIES IN RELATION TO PARENTS' COOPERATION*@

Outcome Parents Cooperative Parents Not Cooperative

Category $\% \quad f$ $\%$

I 2

6.0

1

$7 \cdot ?$

II

11

33.3

1

7.7

III

12

36.4

4

30.8

IV

2

6.0

5

38.5

V

6

18.2

2

15.4

Totals

33

99.9

13

100.1

* $N=46$ because one child's parental rights had been terminated, so no parents were involved in treatment.

$@ x^{2}=8.857, p \leq .05, d . f .=4$, not significant.

\section{Child's Improvement by Discharge}

Of the 47 children, respondents stated that 30 had shown definite improvement, while 13 additional children had improved somewhat. Table XIX presents data on the children's improvement relative to outcome 
categories. The concept of "improvement" implies change relative to the child's beginning status and may not necessarily address the issue of the child's current functioning as being relatively successful or failing. Despite this subtlety, Centers' staff have a high degree of accuracy in predicting current functioning.

TABLE XIX

CHILD'S IMPROVEMENT BY DISCHARGE RELATIVE TO OUTCOME CATEGORY Child's Improvement

\begin{tabular}{|c|c|c|c|c|c|c|}
\hline \multirow{2}{*}{$\begin{array}{l}\text { Outcome } \\
\text { Category }\end{array}$} & \multicolumn{2}{|c|}{ Yes } & \multicolumn{2}{|c|}{ Somewhat } & \multicolumn{2}{|c|}{ No } \\
\hline & $n$ & $\%$ & $\mathrm{n}$ & $\%$ & $\mathrm{n}$ & $\%$ \\
\hline$I$ & 4 & 13.3 & & & & \\
\hline II & 10 & 33.3 & 2 & 15.4 & & \\
\hline III & 10 & 33.3 & 6 & 46.2 & & \\
\hline IV & 3 & 10.0 & 3 & 23.0 & 1 & 25.0 \\
\hline V & 3 & 10.0 & 2 & 15.4 & 3 & 75.0 \\
\hline Totals & 30 & 99.9 & 13 & 100.0 & 4 & 100.0 \\
\hline
\end{tabular}

Reason for Discharge

The respondents were asked why the children were discharged from the Centers. The tabulation of reasons for discharge resulted in 22 "Successful Graduates" reported by the Centers. Some respondents gave more than one reason for discharge. The response marked "Age" ( $f=11$ ) was not included in the interview schedule; these 11 represent all children who left the Centers at or after the age of $11 \frac{1}{2}$, as age 12 is the administratively defined cutoff age. There was some confusion over the termination choices presented in the interview schedule. Thus the 
responses "Parent withdrew child" $(f=8)$ and "Child moved to other institution" ( $f=1)$ are ambiguous, as they represent several differing situations. Several families moved and placed their children in programs in their new communities. In one instance, the purpose of the move was to obtain a more appropriate treatment setting for the child, which was not, however, an institution. The reader should assign no value judgments to the various categories of reasons for discharge. In six cases children were discharged because parents were not cooperative with Center staff during treatment. Finally, 11 children were categorized at discharge as "We did what we could" indicating the Centers believed they could make no further progress.

\section{SUMMARY}

In summary, the variables of sex, length of treatment, amount of time since discharge, parents' cooperativeness, and presence of retardation are all found to have no significant differences when subjected to chi-square tests. Age and type of treatment do appear to have some importance. It is perhaps a good indication that 80 per cent of the parents agreed to participate in the study. Many parents' comments indicated a favorable impression of treatment, either for the child or the entire family. With the basic data results covered, it is appropriate to analyze the implications and conclusions that can be drawn from the results. 
CHAPTER VI

INTERPRETATIONS, CONCLUSIONS AND RECOMMENDATIONS

\section{INTERPRETATIONS AND CONCIUSIONS}

As a result of this DARTS study, it is possible to draw a number of conclusions. It is interesting to note that by dividing the outcome categories into three sections--combined I and II, III, and combined IV and $V$--there is an equal one-third distribution of children in each section. Cunningham's et al., (1956) findings were different with 63 per cent in the satisfactory adjustment category, 22 per cent in partially satisfactory adjustment, and 14 per cent in unsatisfactory adjustment (see Chapter II). However, it should be remembered that the children in Cunninghams's et al., study were treated on an outpatient basis. It is possible to assume that their problems were not as severe as those of the children in this study because their treatment was less comprehensive. The authors believe that the five outcome categories (as defined in Chapter V) are so distinctive that collapsing the catagories into three for all purposes would make the results less clear. However, it does simplify visualizing the relatively equal distribution of children.

The major goal of the DARTS Centers is to prevent children from being institutionalized. This study did not use a control group, nor is it possible to identify which children were definitely institution bound. However, the few number of children in Outcome Category V (see Table II) does indicate that very few children are institutionalized now. It can 
be assumed that the DARTS Centers are a major contributing factor in the prevention of institutionalization.

It is possible to conclude from Tables IV and $V$ that the children entering the Centers at the youngest ages have the best rates of success. Table $V$ clearly shows that 61 per cent of the children in Outcome Categories I and II were between 46 and 93 months of age at program entry.

In talking with the DARTS Center directors, it seemed to be the general consensus that boys achieve a higher success rate than girls. Cunningham et al., found that 75 per cent of the girls in their research made a good home adjustment; whereas, only 60 per cent of the boys adjusted well at home (see Chapter II). According to Table VI, it appears that boys are more successful; however, there is statistically no significant difference. This study included such a small number of girls that it may not be possible to accurately prove or disprove the directors' assumptions.

There was no significant difference between Cohort $A$ and $B$ (see Table VII). This would suggest that the length of time a child is away from the treatment program does not adversely affect the achieved success. However, very few children had reached adolescence at the time of this follow-up study. It is not possible to determine the effect adolescence will have on these children and, thus, whether or not they will remain in their present outcome categories.

Children who were treated exclusively in day treatment seem to achieve higher outcome categories than those children treated either in a mixed program or in a residential program (see Table VIII). There are however a number of possible reasons for this finding which were not tested in this study. The impact of the child remaining within his or her own community with the continuation of existing support systems was not tested. 
The possibility that separating the family from the child removed the family's impetus to cooperate with the Center is another untested factor. There is some belief, as yet untested, that children referred to residential programs have more severe problems, thus, making it more difficult for them to remain in the community or retain family and other supportive ties.

Table IX attempts to show a relationship between the number of months children received treatment and their outcome categories. From this table there appears to be no relationship between these two factors.

No significant difference is found between the success rate of retarded versus nonretarded children (see Table X). It therefore appears that retarded children are capable of achieveing as well in this type of treatment as nonretarded children. However, Table X does indicated a trend toward retarded children doing less well than nonretarded children. Regardless of the outcome category, a large number of children used some type of community service between the time they left the Center and the time of this follow-up study (see Table XI). CSD is the most-used service treating 55 per cent of the children, other mental health programs served 46 per cent and 14 per cent of the children received services from juvenile departments. From this data, it is possible to conclude that community services such as mental health programs and CSD are necessary for the continued improvement and/or lack of deterioration of children having received DARTS Center treatment.

The relationship between the cooperativeness of the parent(s) and the successful outcome of the child does not show a significant difference. However by examining TableXVIII, a trend can be seen which indicates that the more cooperative the parents are the greater the child's chances of 
success. It is possible to assume that the cooperativeness of the parents indicates the existence of a more involved and supportive family unit which could explain this trend.

The authors concluded that the assessment made by DARTS Centers' staff of a child at program termination is predictive of future success. Table XIX indicates that the children who were doing well upon leaving the program continue to do well in the community. However, it should be noted that very few children left the Centers with the staff stating they were not doing well.

\section{RECOMMENDATIONS}

Follow-up studies are becoming increasingly important tools in program evaluation. Six recommendations are being set forth in order for this tool to become even more useful to the DARTS Centers, MHD, and the Legislature.

One of the most severe limitations this study experienced was in the acquisition of information on the children at the time they were accepted and/or entered the DARTS program. It was discovered that the intake information between Centers varied greatly as did the referral system. As a result both CSD and the Center records were often sketchy. Frequently only by talking with a staff person who knew the child at the time of admittance was it possible to obtain adequate information. A standardized intake and reporting system is recommended to insure that consistent information is acquired statewide, and that all referring agencies provide the same information. This process would greatly facilitate future follow-up studies and other types of program evaluations. 
A second recommendation is the institution of an on-going follow-up study conducted by each Center which will systematically feed information back to the three interested groups as well as be available for future research projects. One possible method of on-going follow-up might be the development of a Goal Attainment Scaling Guide on each child.

As previously discussed, the question of confidentiality between MHD and the DARTS Centers is a major stumbling block. Prior to any future research being conducted with these programs, it is recommended that the MHD and the DARTS Centers come to an agreement and issue a position statement regarding confidentiality for research purposes. Thus future researchers will be fully aware from the onset of the flexibilities and limitations of this issue and can plan accordingly. Once the position statement has been drafted, it is recommended that parental permission for follow-up research be obtained as part of each child's admission package.

Table XI illustrates the need for continued community services after the child leaves the DARTS program if positive outcomes are to be maintained. It is recommended that the state of Oregon continue intensifying its support of community-based resources.

Information provided in Tables IV and $\mathrm{V}$ indicate that the earlier problems are identified the better the childrens' chances are for successful treatment. Based on these findings, it is recommended that the state of Oregon encourage methods of early identification and treatment.

As happens with most research, this study opened up the possibility of further research. The authors recommend that MHD continue the research begun in this study. There are at least two ways this research can be 
continued: (1) MHD should continue following these same children over the next five years in order to test the effects of adolescence upon their presently achieved success; and (2) another study could be designed to compare the day, residential, and mixed treatment approaches. Such a study might be able to identify the advantages and disadvantages of these three approaches upon specific behavior problems and provide a better understanding of the effects of these approaches upon family dynamics. This study provides an initial follow-up of 70 children who received treatment through MHD's DARTS program. The findings create as many questions as they do answers. The authors view this study as just a beginning toward understanding the many possible uses of this unique treatment concept. 


\section{A SELECTED BIBLIOGRAPHY}

Bray, J. D. "Programs for Mental or Emotional Disturbances." Salem, Oregon: Mental Health Division, Administrative Rule \#34.005, March 5, 1976.

Brown, Janet L. "Follow Up of Children with Atypical Development (Infantile Psychosis)." American Journal of Orthopsychiatry 33 (April 1963): $855-861$.

Cunningham, James M., M.D.; Westerman, Hester H.; and Fischhoff, Joseph, M.D. "A Follow-up Study of Patients Seen in a Psychiatric Clinic for Children." American Journal of Orthopsychiatry 26 (July 1956): $602-612$.

Davids, Anthony, Ph.D.; Ryan, Richard, M.S.S.S.; and Salvatore, Peter D., M.S.W. "Effectiveness of Residential Treatment for Psychotic and Other Disturbed Children." American Journal of Orthopsychiatry 38 (April 1968): $469-475$.

Davids, Anthony, and Salvatore, Peter. "Residential Treatment of Disturbed Children and Adjustment: A Follow-up." American Journal of Orthopsychiatry 46 (January 1976): 62-73.

Eisenberg, Leon. "The Autistic Child in Adolescence." American Journal of Orthopsychiatry 12 (February 1956): 607-612.

Fuller, Joye M. "An Evaluation of the Home-School Behavioral Management Program Implemented in an Intermediate Classroom for the Emotionally Disturbed." In Dissertation Abstracts International, p. 1941-A 
Ann Arbor, Michigan: University Microfilms, October 1971.

Gold, Joseph, and Reisman, John M. "An Outcome Study of a Day Treatment

Unit School in a Community Mental Health Center." American Journal of Orthopsychiatry 40 (March 1970): 286-287.

Goldfarb, William. "A Follow Up Investigation of Schizophrenic Children

Treated in Residence." Psychosocial Process, Issues in Child

Mental Health I (1970): 9-64.

Greenleigh Associates, Inc. Child Welfare Needs and Services in Oregon:

Report to the Governor's Child Welfare Study Committee. New York:

Greenleigh Associates, Inc., December 1968.

Hoyt, Mary. "History and Functions of Child Study and Treatment Unit."

Salem, Oregon: Memorandum, February 24, 1976. (Typewritten.)

Levitt, E. E.; Beiser, H. R.; and Robertson, R. E. "A Follow-up Evalu-

ation of Cases Treated at a Community Child Guidance Clinic."

American Journal of Orthopsychiatry 29 (April 1959): 337-347.

Menolascino, Frank J., M.D, and Eaton, Louise, M.D. "Psychoses of Child-

hood: A Five Year Follow-up Study of Experiences in a Mental

Retardation Clinic." American Journal of Mental Deficiency 72

(November 1967): $\quad 370-380$.

Peck, Sister Nancy Ann, S.S.S, and Angevine, Krystal. "Follow-up Study

of the Child Diagnostic Center." Masters of Social Work practicum,

Portland State University, $197 ?$.

Rutter, Michael, M.D.; Greenfeld, David, M.D.; and Lockyer, Linda, Ph.D.

"A Five to Fifteen Year Follow-up Study of Infantile Psychosis."

British Journal of Psychiatry 113 (1967): 1169-1199.

Silver, Harold. "Residential Treatment of Emotionally Disturbed Children; 
An Evaluation of 15 Years' Experience." Journal of Jewish Communal Service 38 (Winter 1961): 199-202.

Taylor, Eugene. "Needed Services for Severely Emotionally Disturbed Children in Oregon." Report to the Mental Health Planning Board, 1964.

Zax, M.; Cowen, E. L.; Rappaport, J.; Beach, D. R.; and Laird, J. D. "Follow-up Study of Children Identified Early as Emotionally Disturbed." Journal of Consulting and Clinical Psychology 32 (1968): $369-374$. 


\section{Department of Human Resources \\ MENTAL HEALTH DIVISION}

2575 BITTERN STREET N.E., SALEM, OREGON 97310

Mr. and Mrs. John Doe

1234 Main St.

Anytown, Oregon

Dear Mr, and Mrs. Doe:

[Center's name] and the other day and residential treatment centers in Oregon are part of a follow-up study of children who attended the centers between 1975 and 1977. This study will be useful to the centers and to the Mental Health Division in planning for the future. Your child [child's name] has been selected as one of the participants in the study.

Our two researchers, Doris Beard and Gail Bulkley, will be calling you within the next month to talk about your child's adjustment since leaving the center. In addition to the information from you, we would like to get additional information about your child from Children's Services Division. We are enclosing a written permission form for you to sign, which will allow us to get the additional information needed.

This information is for research purposes only, and all names will be kept confidential.

We hope you will return the signed permission form soon so we can proceed with the study, and have enclosed a stamped, addressed envelope for your convenience. If you have questions, our researchers will be glad to talk about them when they phone you.

Thank you in advance for your cooperation. We look forward to talking with you soon.

Sincerely,

H. Roberts Bagwell, M. D. Consulting Psychiatrist Child and Adolescent Section M. E. D. Program Office

\section{Enclosures}

HRB: gb 
APPENDIX B

FIRST PERMISSION

Consent to Release of Information

I, , am the parent or guardian

OE

I authorize Doris Beard/Gail Bulkley, as representatives of the State of Oregon Mental Health Division, to:

(1) review case files of Children's Services Division regarding my child

(2) interview Children's Services Division caseworkers involved with miv child.

I understand that any information gained from these activities is confidential and will be used only in connection with the Mental Health Division's research follow-up study. I understand that my child's ame will not appear in any pubiished report.

Signed :

Date: 
APPENDIX C

SECOND PERMISSION

CONSENT TO RELEASE OF INFORMATION

I, am the parent

or guardian of

I authorize Doris Beard, Gail Bulkley, and H. Roberts Bagwell, as representatives of the State of Oregon Mental Health Division, to:

(1) review case files of Children's Services Division and of regarding my child

(2) interview Children's Services Division caseworkers involved with my child.

I understand that this consent to release information may be revoked by me at any time, except to the extent that interviews and case file review authorized here has already taken place.

I Inderstand that any information gained from these activities is confidential and will be used only in connection with the Mental Health Division's research follow-up study. I understand that my child's name will not appear in any published report.

This consent, unless expressly revoled earlier, expires on December 1, 1978.

Signed :

Date: 
APPENDIX D

FOLLOW-UP LETTER

Department of Human Resources

MENTAL HEALTH DIVISION

2575 BITTERN STREET N.E., SALEM, OREGON 97310

Mr. and Mrs. John Doe

1234 Main St.

Anytown, Oregon

Dear Mr. and Mrs. Doe:

The follow-up study I discussed with you on the telephone is continuing. I am now ready to talk with the Center and Children's Services Division about [child's name]'s situation upon entering [Center's name]. However, I cannot do that without your signature on the Release of Information form. I am enclosing another form for your signature and would appreciate your returning it as soon as possible.

Thank you very much for your cooperation with this study.

Sincerely,

Doris Beard

Gail Bulkley

Enclosure

$g b$ 
Length of Treatment:

Center:

Situation at Entry into Program

Living situation:

parents

foster home/shelter

Other

School status:

In

Out

Tutor

other

Behavioral categories at entry:

Yes

No

running

sexual

sexual abuse

overly aggressive

demands attention

non-compliance

adult relations

fire setting

peer relations

familial relations

truancy

short attention span

low level of frustration

low self-image, withdrawn, suicidal thoughts, depression, loneliness.

excessive worrying - unreasonable fears self-help - problem solving

substance abuse 
Other presenting problems:

\section{Situation at Departure from Program}

Were the parents cooperative?

Comments:

Did the child improve? yes no As evidenced by:

Did the child improve academically? yes somewhat no

Reason for termination: inappropriate placement successful graduate parent not cooperative parent withdrew child child moved to other institution "We did what we could." Other

What was discharge plan?

\section{Did staff like the discharge plan?} yes no can't tell

Is any DART staff now in touch with the family or child? yes no Who?

Data gathered by:

Date: 
CHILD QUESTIONNAIRE

Data Sheet

Identifying Information

Child's Name:

Code:

CSD Number:

Center:

Termination Date:

Source of Data, Relationship to Child:

Phone:

Personal Interview? Written records?

Specify:

Interviewee's Frequency of Contact with Child: Once/week Once/month Once/3 months other

Wardship:

Parent's Name:

Address:

Phone:

Data gathered by:

Date: 
INTERVAL HISTORY

Where living at date of termination from program?

\section{Dates}

From To

\section{CURRENT ADJUSTMENT}

For present living situation

Is the situation stable? Comments

Is a move anticipated? yes no To where? Why necessary?

Problem behaviors (if any)
Living Situation (be specific, i.e., name of foster family if in foster care, etc.) 
For present school situation

At.tending what school?

Current grade?

Are special education services being provided? yes

no

What are they?

Academic progress

Good or satisfactory
___ Somewhat problematic

As evidenced by

A serious problem

As evidenced by

Are there behavioral problems at school? yes

no

What are they? 
After Care Services to Child

Active CSD casework? yes

no

When?

How long?

Comments:

Any mental health or other counseling treatment? yes

no

Where?

How 1ong?

Involvement with juvenile authorities? yes no.

Comments:

Health problems of child? yes no

Comments:

Medications: 
Broad Behavioral Categories (indicate child's identified problems):

Yes No

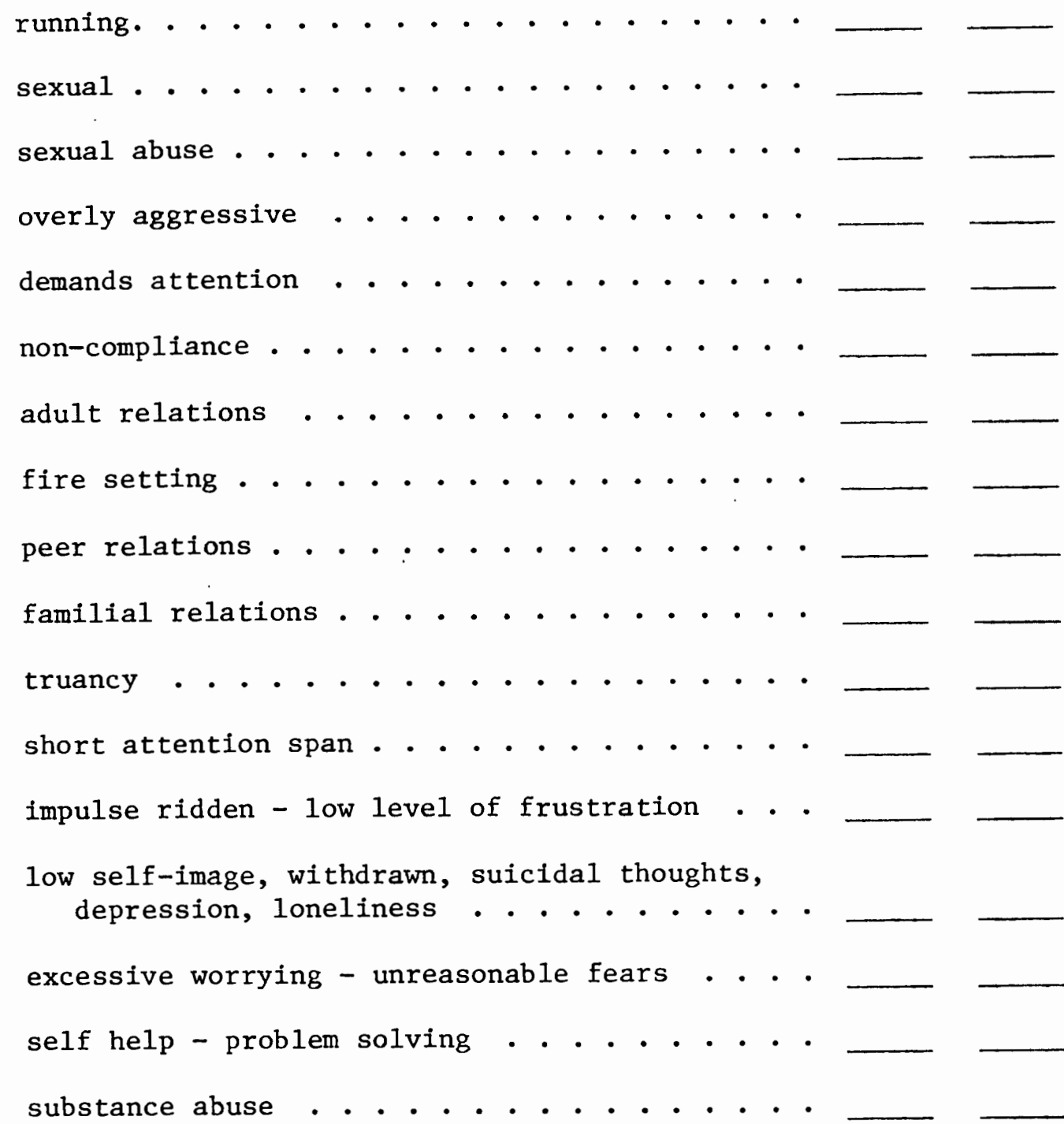

Other Life Events, Beyond Child's Control

(Examples: death, divorce, unemployment)

Other 